Research Article

\title{
Evaluation of Edible Quality of Sorghum Based on Principal Component Analysis
}

\author{
Chunlei Ni $\mathbb{D}^{1},{ }^{1}$ Shan Zhang $\mathbb{D}^{1},{ }^{1}$ Gaopeng Zhang, ${ }^{1}$ Jianjun Cheng $\mathbb{D},{ }^{1}$ \\ and Huanyu Zheng $\mathbb{D}^{1,2,3}$ \\ ${ }^{1}$ College of Food Science, Northeast Agricultural University, Harbin 150030, China \\ ${ }^{2}$ Heilongjiang Green Food Science Research Institute, Harbin 150028, China \\ ${ }^{3}$ National Research Center of Soybean Engineering and Technology, Harbin 150028, China
}

Correspondence should be addressed to Jianjun Cheng; jjcheng@neau.edu.cn and Huanyu Zheng; zhenghuanyu1@163.com

Received 14 June 2019; Accepted 5 September 2019; Published 24 September 2019

Academic Editor: João Paulo Leal

Copyright (c) 2019 Chunlei Ni et al. This is an open access article distributed under the Creative Commons Attribution License, which permits unrestricted use, distribution, and reproduction in any medium, provided the original work is properly cited.

Sorghum (Sorghum bicolor (L.) Moench) is one of the most important cereals in the Northeast China. The physicochemical, pasting, texture, and cooking properties of 21 sorghum varieties were determined, which were mainly cultivated in Northeast China. Then, the evaluation of edible quality of sorghum was based on principal component analysis and fitted with the score of sensory evaluation. Five principal components (PCs) with a cumulative contribution rate of $86.19 \%$ could be picked out to describe the taste, pasting, flavor, cooking, and variety of sorghum, respectively. And a comprehensive equation of sorghum edible quality in Northeast China was constructed which was $Z=0.45 F_{1}+0.25 F_{2}+0.12 F_{3}+0.10 F_{4}+0.08 F_{5}$. The edible quality of No. 14 and No. 15 was the best. The sensory evaluation was used to verify the above equation with the fitting coefficient of 0.81 , which indicated that the equation could be more accurate to evaluate the edible quality of sorghum in Northeast China.

\section{Introduction}

Sorghum (Sorghum bicolor (L.) Moench) is the fifth most produced cereal after wheat, rice, maize, and barley $[1,2]$ and is drought tolerant, resistant to water logging, and grows in various soil conditions [3]. In recent years, sorghum cultivation has been concentrated in Northeast China, and the yield accounted for $62 \%$ of the National Sorghum Yield in 2016 (data source: Department of Market and Economic Information, Ministry of Agriculture, China). Because sorghum is rich in starch and protein, it can be regarded as a substitute for the common cereals such as rice, wheat, millet, and soybean. The consumption of whole sorghum grains would contribute toward health benefits through bioactive compounds such as fiber and phenolics [4]. In Western countries such as the United States, Australia, and Brazil, sorghum is developed and cultivated primarily for animal feeding, while in semiarid regions of the world, it is mainly used in human feeding as coarse grains [5-7]. In China, the history of Kaoliang Spirit has been more than 2500 years [8]. With the short of pure water resources, sorghum which is an ecologically friendly and tolerant crop will become an important crop in the future. As sorghum is one of the three main grains in China, how to evaluate its edible quality scientifically and realize its value better is a question worthy of in-depth study.

Nowadays, the evaluation of the edible quality of cereals is mainly focused on the fine grains such as rice and wheat. Evaluation methods include sensory evaluation and instrumental analysis. Sensory evaluation was affected by the regional eating habits, environment of the participants, and difficulty in quantitatively describing the food taste [9]. Some scholars have made comprehensive analysis of cereal quality by means of instrument and physicochemical characteristics that include the texture tester and the rapid viscosity analyser (RVA). The hardness and stickiness in the texture characteristics can be used to evaluate the softness and looseness of rice, while the pasting temperature and setback viscosity of gelatinized flour starch pastes can be used to evaluate the cooking time and the texture of meal $[10,11]$. Based on the analysis of the correlation among the gelatinization properties, texture properties, and sensory 
evaluation of cereals, a method for predicting the texture of rice can be established [12]. In addition, physicochemical components are often used to analyse the quality of rice taste. The composition content and structure of starch were the important factors of edible quality, while protein, moisture, and ash content were significantly correlated with taste, appearance, and comprehensive score of rice [13-15]. Literature review shows the varieties of rice with better taste quality had a shorter cooking time, higher iodine blue value, and lower water absorption [16]. So far, principal component analysis, cluster analysis, and discriminant analysis are the main methods used in the comprehensive analysis of cereals. However, principal component analysis is the most commonly method for cereal quality evaluation.

Principal component analysis (PCA) is an analytical method for transforming multiple indexes into fewer new ones [17]. PCA combined with the determination of cereal quality characteristics can simplify the cereal quality index into several principal components with a cumulative contribution rate of more than $80 \%$ and then analysed the edible quality of cereals to study the effects of physicochemical components and quality characteristics of cereals on edible quality $[18,19]$. The principal component analysis (PCA) was used to study the edible quality of rice, the suitable processability of sweet waxy corn, and the physical properties and processing characteristics of oat grains [18, 20, 21]. Besides, it can be used to establish the evaluation model of edible quality which included Indica rice cake, Japonica rice, and Indica rice [22-24]. There are relatively few studies on the evaluation of sorghum edible quality.

The aim of the paper was to evaluate the edible quality of sorghum. 21 sorghum varieties which were mainly cultivated in Northeast China were selected to analyse their physicochemical, pasting, texture, and cooking properties and edible quality. Then, the properties of sorghum were analysed by PCA, and the evaluation equation was obtained. Finally, the equation was fitted with the score of sensory evaluation. The results showed it was more intuitive and objective and provided a theoretical basis for the edible quality of sorghum.

\section{Materials and Methods}

2.1. Materials. Nos. 1-13 sorghum (Sorghum bicolor (L.) Moench) varieties were provided by Jilin Academy of Agricultural Sciences (Jilin province, China), which were Z1001-Z1013. Nos. 14-21 were provided by Heilongjiang Academy of Agricultural Sciences (Heilongjiang Province, China), which were 16-5071, 16-5072, Dragon Miscellaneous 17, Dragon Miscellaneous 18, Dragon Miscellaneous 16, Dragon Glutinous 13-2, Dragon Rice Grain 2, and Dragon Rice Grain 1. All chemicals were analytical grade reagents.

2.2. Proximate Analysis. Moisture content was determined according to the procedure in AACC (44-19,2000). Ash content was determined by dry ashing in a furnace oven at $550^{\circ} \mathrm{C}$ (AACC 8-01,2000). The crude protein was calculated by converting the nitrogen content determined by the
Kjeldahl method $(\mathrm{N} * 6.25)$ (AACC 46-12,2000). Crude lipid, using a Soxhlet apparatus (AACC 30-25,2000), was also determined. Starch content was determined according to the procedure in AACC (76.13.2000). Tannin content was determined referring to the method of Maxson by spectrophotometry [25].

2.3. RVA Pasting Properties. Sorghum pasting properties were determined using a Rapid Visco Analyser (RVA, Super3, Newport Scientific, Warriewood, Australia). Flour ( $3.00 \mathrm{~g}$, based on $12 \%$ moisture) was mixed with $25 \mathrm{~g}$ of distilled water in an RVA sample canister. The RVA was run using Thermocline for Windows software (Version 1.2). The Rice Method 1 program was used with heating and cooling cycle set as follows: (1) holding at $50^{\circ} \mathrm{C}$ for $1 \mathrm{~min},(2)$ heated to $95^{\circ} \mathrm{C}$ in $3.8 \mathrm{~min}$, (3) holding at $95^{\circ} \mathrm{C}$ for $2.5 \mathrm{~min}$, (4) cooling to $50^{\circ} \mathrm{C}$ in $3.8 \mathrm{~min}$, and (5) holding at $50^{\circ} \mathrm{C}$ in $1.4 \mathrm{~min}$. The pasting temperature (PT), peak viscosity $(\mathrm{PV})$, breakdown (BD), and setback (SB) were recorded form the Thermocline for Windows software (Version 1.2) [26].

\subsection{Cooking Characteristics}

2.4.1. Preparation of Sorghum Rice. Experiments were conducted with an automatic rice cooker (CFXB4003-A1, $4.0 \mathrm{~L}, 700 \mathrm{~W}, 220 \mathrm{~V}, 50 \mathrm{~Hz}$, Guangzhou domestic appliance Ltd., China). $1000 \mathrm{~g}$ sorghum rice was soaked in a pot for $30 \mathrm{~min}$ with $1500 \mathrm{~mL}$ of tap water. After the sorghum rice cooked for $40 \mathrm{~min}$, the thermostat coupled with microswitch automatically switched off the automatic rice cooker. The cooked sorghum rice samples were held in the rice cooker for an additional $20 \mathrm{~min}$. Finally, the cooked sorghum rice was obtained.

2.4.2. Water Absorption Rate. The sorghum sample of a certain mass was weighed and recorded as $M_{1}$, which was placed in a beaker. Then, a certain volume of distilled water was added, cooked in a boiling water bath for 20 minutes, and finally cooled to room temperature, and the weight of $M_{2}$ was recorded. The calculation formula is as follows [27]:

$$
\text { Water absorption rate }(\%)=\frac{M_{2}}{M_{1}} \times 100 \% \text {. }
$$

2.4.3. Volume Expansion Ratio. The volume of sorghum rice sample before and after cooking was measured by the drainage method, as described in [16]. The sample of sorghum rice of certain mass was poured into the measuring cylinder that contains $50 \mathrm{~mL}$ distilled water, and the volume $V_{1}$ was recorded. Then, the sorghum rice sample was cooked in a boiling water bath for 20 minutes. After cooking, the sample was poured into the same measuring cylinder as above, and the volume $V_{2}$ was recorded. The formula is as follows:

$$
\text { Volume Expansion ratio }=\frac{V_{2}-50}{V_{1}-50} \times 100 \% \text {. }
$$


2.4.4. Iodine Blue Value. The rice soup was cooled to room temperature and diluted to $100 \mathrm{~mL}$. After [27] centrifugation (Allegra X-30R Multifunctional Centrifuge, American Beckman Coulter, USA), $1.0 \mathrm{~mL}$ rice soup was added to $50 \mathrm{~mL}$ distilled water and then $5 \mathrm{~mL}$ of $0.5 \mathrm{~mol} / \mathrm{L} \mathrm{HCl} \mathrm{so-}$ lution and $1 \mathrm{~mL}$ of $0.2 \mathrm{~g} / 100 \mathrm{~mL}$ of iodine reagent were added; finally, the volume was adjusted to $100 \mathrm{~mL}$. The absorbance was measured at a wavelength of $660 \mathrm{~nm}$ by Ultraviolet visible spectrophotometer (UVmini-1240, Shimadzu Co., Ltd, Japan). The iodine blue value of rice soup is expressed by absorbance [28].

2.5. Textural Profile Analysis. Textural profile analysis (TPA) of the cooked sorghum rice was performed using a texture analyser (TA.XT.plus, Texture Technologies Corp., UK). The hardness, stickiness, adhesiveness, chewiness, and responsiveness were determined. The texture was determined according to the method of $\mathrm{Yu}$ et al. [29] with minor modifications. The texture analyser was linked to a computer that recorded the data via a software program called Texture Expert Excede Version 1.0 (Stable Micro Systems Software). The P50 probe was used to compress 3 sorghum rice grains, under the compression distance of $1.4 \mathrm{~mm}$ and the trigger point force of $10.0 \mathrm{~g}$, with pretest speed, test speed, and posttest speed of $10.0 \mathrm{~mm} / \mathrm{s}, 0.5 \mathrm{~mm} / \mathrm{s}$, and $5.0 \mathrm{~mm} / \mathrm{s}$, respectively. All textural analyses were replicated six times per sample, and the results are presented as mean values.

2.6. Sensory Evaluation. The sensory analysis of the cooked sorghum rice was carried out in laboratory conditions. Sensory assessments were determined by 20 trained panelists (staff aged from 30 to 40 years old and graduate students aged from 20 to 30 years old): ten females and ten males. The evaluation was carried out using the 100-point scale test with the distinctions of quality (smell, appearance, taste, texture, and acceptability) [30,31], and the results are shown in Table 1 . In the process of sensory quality evaluation, 4 servings of sorghum rice were tasted each time, and the evaluation time was arranged 1 hour before and 2 hours after meal. The average value of each evaluator was calculated as the comprehensive evaluation value of sorghum rice, and the edible quality of sorghum was measured.

2.7. Principal Component Analysis. Principal component analysis (PCA) converts observations of correlated variables into a set of linearly uncorrelated orthogonal variables (principal components, PCs), ordered in such a way that each PC has the largest possible variance under the constraint of being orthogonal to all preceding components [32].

The $p$ variables of $n$ samples $\left(X_{1}, X_{2}, \ldots, X p\right)$ was transformed into $k(k<p)$ complex variables $\left(F_{1}, F_{2}, \ldots, F_{k}\right)$, which was the linear combination of original variables. Comprehensive variables $F_{1}, F_{2}, \ldots, F_{k}$ were called the first, second, ..., the $k_{\mathrm{th}}$ PC of the original variable, respectively:

$$
\begin{aligned}
& F_{1}=a_{11} X_{1}+a_{21} X_{2}+\cdots+a_{p 1} X_{p} \\
& F_{2}=a_{12} X_{1}+a_{22} X_{2}+\cdots+a_{p 2} X_{p} \\
& \cdots \\
& F_{k}=a_{1 k} X_{1}+a_{2 k} X_{2}+\cdots+a_{p k} X_{p} .
\end{aligned}
$$

The quantized values of each sample are weighted by the ratio $\beta_{i}(i=1,2, \ldots, k)$ of the $k$ PCs of different eigenvalues, and the comprehensive evaluation function: $Z=\beta_{1} F_{1}+\beta_{2} F_{2}+\cdots+\beta_{k} F_{k}$ was used to calculate the scores of sorghum rice samples [33].

2.8. Statistical Analysis. SPSS software (Version 17.0, SPSS Inc., Chicago, USA) was used to analyse the data. The means were compared using Pearson's test at a 5\% level of significance using the analysis of variance (ANOVA). Analyses of the samples were completed in triplicate, and the data were expressed as the mean \pm standard deviation.

\section{Results and Discussion}

3.1. Proximate Analysis of Sorghum. There were significant differences in physicochemical components among different sorghum grain varieties $(P<0.05)$, as shown in Table 2 . Starch and protein were the main components of sorghum grains and played an extremely important role in the cooking process. The starch content of 21 sorghum varieties ranged from $68.15 \%$ to $79.39 \%$, with an average content of $73.24 \%$, which was lower than the average starch content in other cereals (78\% of rice and $75 \%$ of corn) [34].The protein content varied from $6.75 \%$ to $11.23 \%$. Most of them were higher than $8.25 \%$ except for No. 2 and Nos. 18-21. The result showed there were regional differences of the starch content and protein content, and sorghum planted in Heilongjiang are generally lower than those in Jilin. Therefore, the difference in starch and protein content among different varieties may be one of the main factors causing the difference in taste quality [35].

The moisture and tannin in sorghum were $9.46 \%$ $14.42 \%$ and $0.00 \% \sim 0.12 \%$, respectively. Water can bind to macromolecules such as protein and starch, which has an important effect on starch gelatinization and edible quality of cereals. Especially, the content of tannin in No. 13 was 0, which may have a positive effect on the good taste quality of sorghum rice. The range of the oil content was $1.30 \%$ 3.93\%, with the highest content in No. 15 Sorghum of $3.93 \%$, which was much higher than that in rice $(0.24 \% \sim 0.67 \%)$. The oil in sorghum can improve the edible quality of rice and give the special flavor of rice. However, the oil forms the complex with starch, which inhibits the gelatinization of starch and affects the taste quality of rice [36].

3.2. Pasting Properties. The significant differences in pasting properties among different varieties are shown in Table 2 $(P<0.05)$. Gelatinization is one of the physicochemical properties of starch, and it is an important indicator to de- 
TABLE 1: The sensory evaluation of sorghum rice.

\begin{tabular}{|c|c|c|c|c|c|c|c|c|c|c|}
\hline Variety & $\begin{array}{c}\text { Smell } \\
(20)\end{array}$ & $\begin{array}{l}\text { Color } \\
(7)\end{array}$ & $\begin{array}{c}\text { Appearance } \\
(20) \\
\text { Glossiness } \\
(8)\end{array}$ & $\begin{array}{l}\text { Rice grain } \\
\text { integrity (5) }\end{array}$ & $\begin{array}{c}\text { Stickiness } \\
(10)\end{array}$ & $\begin{array}{c}\text { Acceptability } \\
(30) \\
\text { Elasticity } \\
(10)\end{array}$ & $\begin{array}{l}\text { Soft and hard } \\
\text { degree (10) }\end{array}$ & $\begin{array}{l}\text { Taste } \\
(25)\end{array}$ & $\begin{array}{c}\text { Texture } \\
\text { (5) }\end{array}$ & $\begin{array}{l}\text { Score } \\
(100)\end{array}$ \\
\hline 1 & 14.00 & 5.50 & 5.00 & 4.50 & 5.50 & 5.00 & 6.50 & 18.00 & 3.80 & 67.80 \\
\hline 2 & 16.20 & 5.65 & 6.50 & 3.30 & 6.00 & 6.00 & 7.50 & 18.00 & 3.80 & 72.95 \\
\hline 3 & 15.00 & 5.00 & 5.25 & 4.25 & 5.40 & 4.50 & 6.50 & 17.50 & 3.50 & 66.90 \\
\hline 4 & 16.40 & 4.50 & 6.80 & 3.60 & 5.60 & 4.50 & 6.20 & 18.00 & 3.00 & 68.60 \\
\hline 5 & 16.50 & 5.00 & 4.80 & 4.30 & 5.50 & 5.00 & 7.20 & 17.00 & 3.75 & 69.05 \\
\hline 6 & 13.60 & 4.50 & 5.80 & 3.20 & 5.75 & 4.00 & 6.30 & 19.00 & 3.50 & 65.65 \\
\hline 7 & 13.65 & 3.80 & 5.75 & 3.50 & 6.80 & 5.50 & 7.20 & 18.00 & 3.50 & 67.70 \\
\hline 8 & 13.80 & 6.00 & 5.75 & 3.00 & 6.50 & 4.50 & 6.50 & 18.00 & 3.50 & 67.55 \\
\hline 9 & 15.00 & 4.50 & 5.00 & 3.50 & 5.80 & 5.50 & 6.00 & 17.50 & 4.00 & 66.80 \\
\hline 10 & 16.40 & 5.60 & 5.25 & 4.25 & 4.50 & 5.00 & 5.80 & 18.00 & 3.35 & 68.15 \\
\hline 11 & 15.00 & 4.50 & 5.30 & 3.30 & 4.20 & 5.50 & 6.50 & 16.50 & 3.90 & 64.70 \\
\hline 12 & 15.00 & 5.00 & 5.40 & 3.40 & 4.00 & 5.50 & 6.50 & 16.50 & 3.50 & 64.80 \\
\hline 13 & 16.70 & 6.80 & 5.60 & 4.30 & 3.80 & 3.00 & 6.20 & 17.00 & 2.85 & 66.25 \\
\hline 14 & 15.00 & 4.50 & 7.00 & 4.80 & 8.20 & 6.50 & 8.50 & 20.00 & 4.50 & 79.00 \\
\hline 15 & 17.00 & 4.50 & 7.00 & 4.80 & 8.25 & 7.00 & 8.20 & 21.00 & 4.50 & 82.25 \\
\hline 16 & 16.50 & 5.00 & 6.50 & 4.30 & 6.00 & 6.00 & 7.50 & 18.50 & 3.75 & 74.05 \\
\hline 17 & 15.00 & 5.85 & 5.30 & 3.80 & 6.00 & 4.75 & 6.50 & 17.00 & 3.50 & 67.70 \\
\hline 18 & 14.00 & 6.20 & 7.00 & 2.80 & 5.80 & 4.00 & 8.00 & 16.50 & 3.80 & 68.10 \\
\hline 19 & 14.60 & 4.00 & 6.80 & 4.30 & 8.30 & 6.00 & 7.25 & 19.00 & 4.85 & 75.10 \\
\hline 20 & 14.50 & 6.70 & 6.50 & 3.40 & 7.80 & 7.00 & 8.75 & 18.00 & 4.50 & 77.15 \\
\hline 21 & 14.50 & 6.60 & 5.70 & 4.00 & 7.50 & 5.50 & 7.50 & 20.00 & 3.50 & 74.80 \\
\hline
\end{tabular}

termine the cooking quality and edible quality of rice. The PT of 21 sorghum varieties ranged from $71.1^{\circ} \mathrm{C}$ to $80.7^{\circ} \mathrm{C}$, and the PT of sorghum from Jilin $\left(74.8^{\circ} \mathrm{C} \sim 80.7^{\circ} \mathrm{C}\right)$ was significantly higher than that of Heilongjiang $\left(71.1^{\circ} \mathrm{C} \sim 74.4^{\circ} \mathrm{C}\right)(P<0.05)$, which indicated that sorghum from Jilin was not easy to gelatinize. Compared to the analysis of protein content in different sorghum varieties, the protein content of sorghum planted in Jilin was generally high, which was consistent with the results of Chandrashekar and Kirleis [37] that higher protein content would inhibit gelatinization of sorghum starch [37, 38].

The PV of 21 sorghum varieties was concentrated in the range of $3000 \sim 4000 \mathrm{cP}$, while the $\mathrm{PV}$ of sorghum varieties Nos. 14, 15, and 19 from Heilongjiang was $2491 \mathrm{cP}, 2691 \mathrm{cP}$, and $2498 \mathrm{cP}$, respectively, which were much lower than that of other varieties. The results indicated that the starch granules of the three varieties were easy to expand during cooking and gelatinization and easy to be softened and break during the thickening process [39].

The $\mathrm{BD}$ is a measure of the difficulty of particle structure disintegration in the heating process of starch [40]. The BD varied from $539 \mathrm{cP}$ to $2918 \mathrm{cP}$, which indicated that the effect of starch on the taste quality of sorghum was different. The SB of different varieties varied widely, ranging from 387 to $2061 \mathrm{cP}$. The SB of sorghum varieties Nos. 14, 15, and 19 was $387 \mathrm{cP}$, $422 \mathrm{cP}$, and $627 \mathrm{cP}$, respectively, while the SB of other sorghum varieties was above $1500 \mathrm{cP}$. This may be related to the starch content; that is, the varieties with a lower amylose content have lower SB. After cooking and gelatinization, the aging rate of starch is slower, and the taste quality of rice is better [29].

3.3. Cooking Characteristics. The significant differences in volume expansion ratio, water absorption rate, and iodide blue value among different varieties $(P<0.05)$ are shown in Figure 1. It can be seen from Figures 1(a) and 1(b) that the volume expansion ratio and the water absorption rate of Nos. 4, 8, 9, and 12 were 270.85\%, 276.23\%, 288.23\%, and $279.28 \%$ and $242.95 \%, 242.19 \%, 241.86 \%$, and $236.52 \%$, respectively, which were significantly higher than other varieties $(P<0.05)$. The water absorption rate and the volume expansion ratio of rice grains were the important indicators of cooking characteristics. And the bigger the grains are, the higher the fluffy quality of rice is; more likely, it was that rice grains appear to explode [15]. So that the acceptability of Nos. 4, 8, 9, and 12 with high water absorption rate and volume expansion ratio may be poor (Table 1). It could be seen from Figure 1(c) that the iodine blue value of sorghum ranged from 0.071 to 1.561 , and most of the varieties were concentrated in the range of 0.650 to 0.850 . However, the iodine blue value of Nos. 14, 15, 19, 20, and 21 in Heilongjiang was 0.122, 0.123, 0.297, 0.161, and 0.071 , respectively, which were significantly lower than those of other varieties $(P<0.05)$. At the same time, compared with Table 3, it was found that the PV and SB of Nos. 14, 15, and 19 with a lower iodine blue value were also significantly lower than other sorghum varieties $(P<0.05)$. It indicated that the starch granules of these varieties were easily to be broken, easy to gelatinize, and not easy to regenerate during the cooking process and with better edible quality. Some studies have shown that the cooking quality of sorghum was mainly affected by the composition and gelation of starch. The gelation humidity of amylose is high, so that the water absorption and the expansion rate was large, which led to the dryness of cooked rice. Meanwhile, the more the amylose content, the more the starch content dissolved in the cooking process, resulting in the larger iodine blue value of 


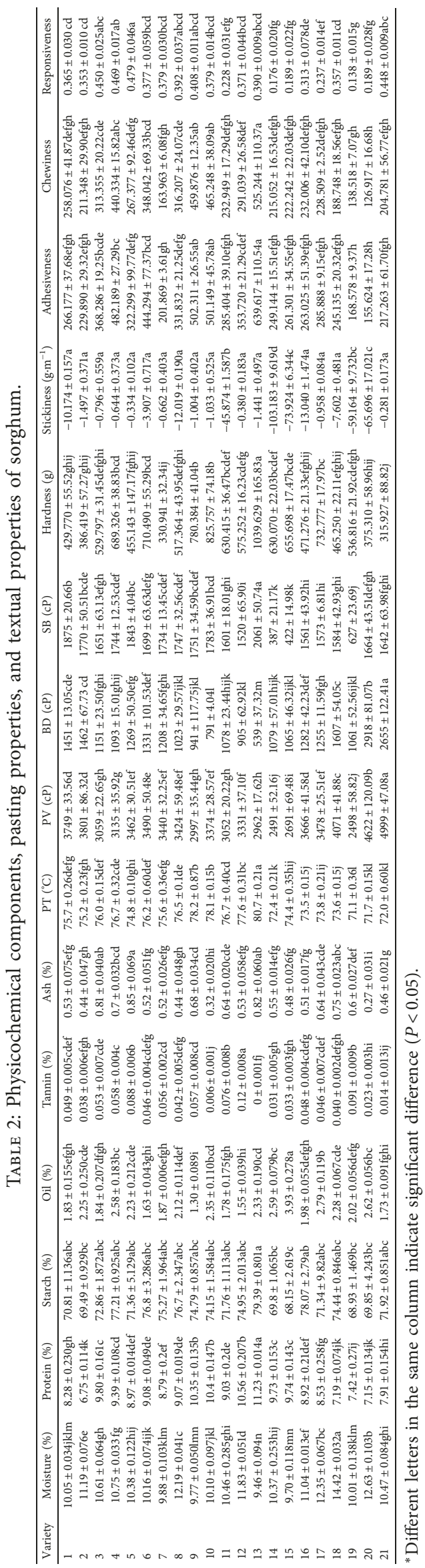




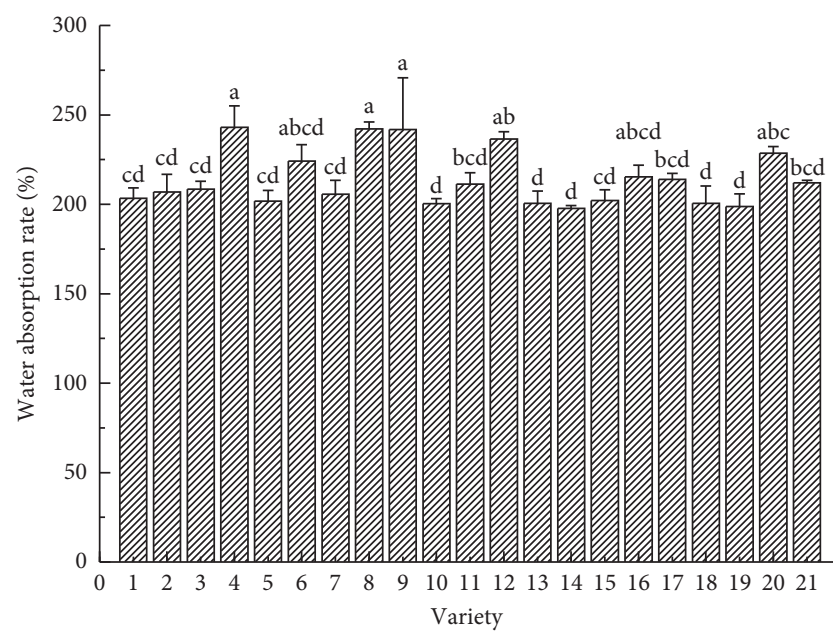

(a)

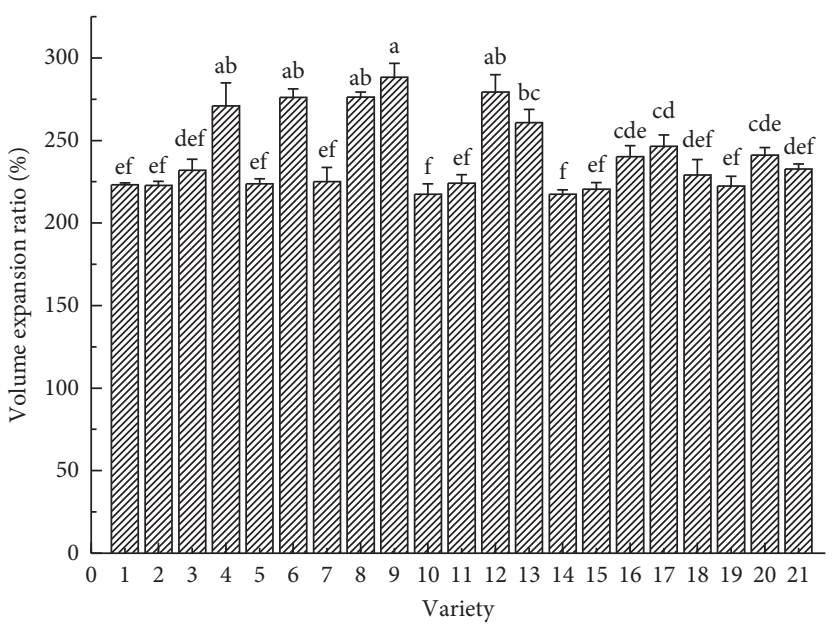

(b)

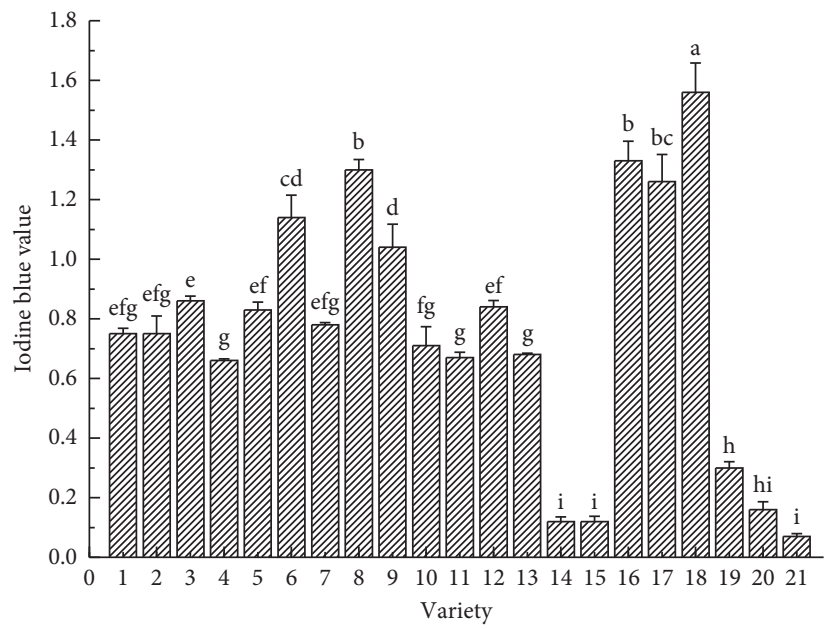

(c)

FIgURE 1: Cooking characteristics of sorghum: (a) water absorption rate; (b) volume expansion ratio; (c) iodine blue value.

TABLE 3: The loadings of the individual variables as calculated during PCA.

\begin{tabular}{lccccc}
\hline Individual variable & $F_{1}$ & $F_{2}$ & $F_{3}$ & $F_{4}$ & $F_{5}$ \\
\hline$X_{1}$ & -0.250 & 0.563 & -0.176 & 0.289 & 0.631 \\
$X_{2}$ & 0.733 & -0.503 & 0.075 & 0.094 & -0.129 \\
$X_{3}$ & 0.796 & 0.264 & 0.043 & 0.114 & 0.134 \\
$X_{4}$ & -0.367 & -0.480 & 0.323 & 0.138 & 0.490 \\
$X_{5}$ & 0.058 & 0.050 & -0.902 & 0.027 & -0.276 \\
$X_{6}$ & 0.430 & -0.139 & -0.429 & -0.457 & 0.219 \\
$X_{7}$ & 0.489 & 0.450 & -0.388 & -0.045 & 0.525 \\
$X_{8}$ & 0.675 & 0.253 & -0.129 & 0.614 & -0.080 \\
$X_{9}$ & 0.400 & 0.394 & -0.134 & 0.741 & -0.208 \\
$X_{10}$ & 0.900 & -0.120 & 0.105 & -0.062 & -0.039 \\
$X_{11}$ & -0.270 & 0.842 & 0.411 & -0.025 & -0.012 \\
$X_{12}$ & -0.625 & 0.590 & 0.351 & 0.121 & -0.138 \\
$X_{13}$ & 0.570 & 0.673 & 0.205 & -0.229 & -0.010 \\
$X_{14}$ & 0.666 & -0.578 & 0.175 & 0.164 & 0.236 \\
$X_{15}$ & 0.641 & 0.604 & -0.003 & -0.327 & 0.017 \\
$X_{16}$ & 0.926 & -0.215 & 0.241 & 0.020 & 0.040 \\
$X_{17}$ & 0.913 & -0.191 & 0.284 & 0.035 & -0.016 \\
$X_{18}$ & 0.648 & 0.496 & 0.114 & -0.348 & -0.171 \\
\hline
\end{tabular}

soup and the worse grain integrity and acceptability (stickiness and elasticity) of sorghum rice [41]. On the contrary, the sorghum rice with more amylopectin content was wet, and the taste was better [42].

3.4. Textural Characteristics. The significant differences in textural properties among different varieties $(P<0.05)$ are shown in Table 2. The hardness of sorghum rice ranged from 315.93 to $1039.63 \mathrm{~g}$, and most of the varieties were concentrated in the range of $300 \mathrm{~g}$ to $600 \mathrm{~g}$. It was not difficult to find that the stickiness of 21 varities of sorghum is generally very low, only the Jilin No. 11 and Heilongjiang Nos. 14, 15, 19, and 20 with higher stickiness, which are $-45.874 \mathrm{~g} \cdot \mathrm{m}^{-1},-103.183 \mathrm{~g} \cdot \mathrm{m}^{-1}$, $-73.924 \mathrm{~g} \cdot \mathrm{m}^{-1},-59.164 \mathrm{~g} \cdot \mathrm{m}^{-1}$, and $-65.696 \mathrm{~g} \cdot \mathrm{m}^{-1}$, respectively. The stickiness of No. 14 was the highest, which was significantly higher than that of other sorghum varieties $(P<0.05)$. Stickiness of rice was related to the composition of starch; that is, the varieties with a lower amylose content have higher stickiness [43]. The results also verified the experimental iodine blue value; that is, in sorghum varieties with a low iodine blue 


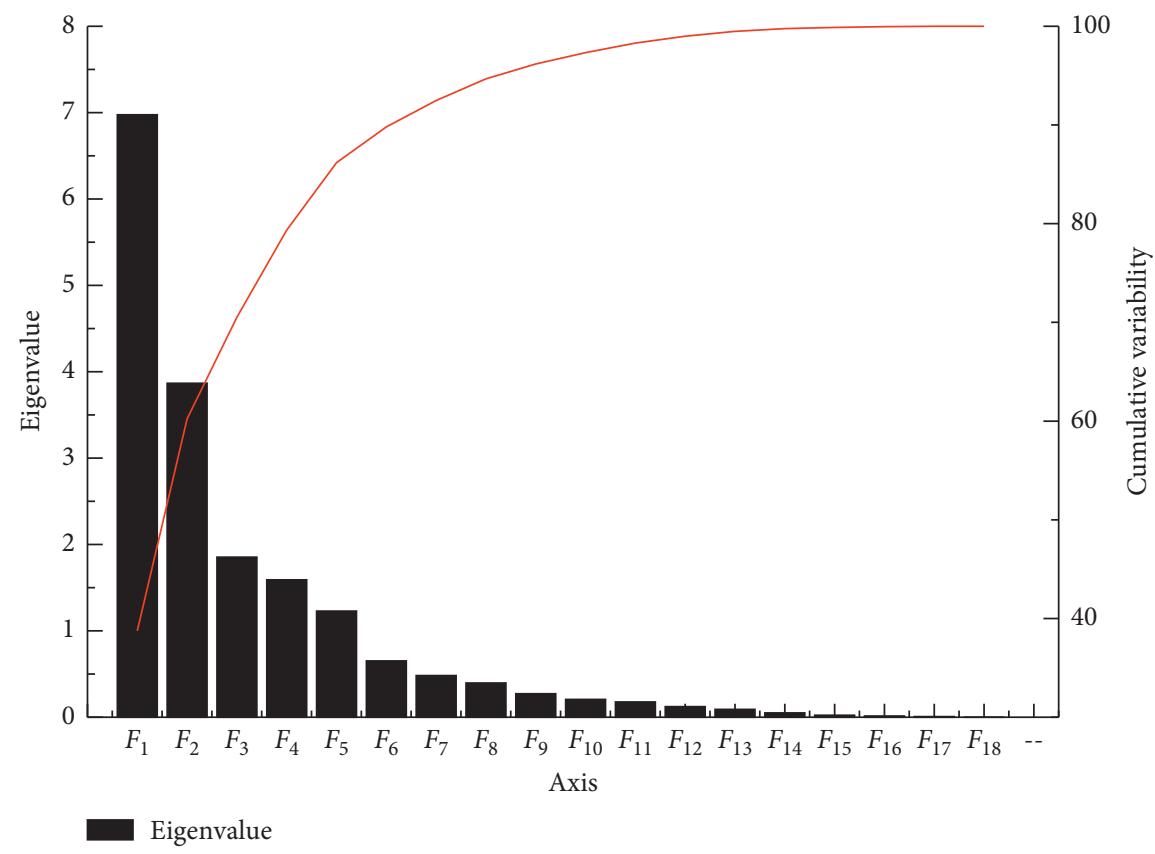

FIgURE 2: Scree plot of the eigenvalues of PCA.

value, the rice soup will be more viscous, steamed rice stickiness was higher, and acceptability was better [44]. The hardness and stickiness were the main indicators to evaluate the quality of sorghum rice. The rice with a lower hardness and higher stickiness had shorter cooking time and better taste quality [15]. The chewiness is a comprehensive embodiment of adhesiveness and elasticity, which is related to the content of protein and starch [45]. No. 13, for example, which has the highest chewiness and adhesiveness, also has the highest protein content. In addition, there were significant differences in responsiveness among different varieties $(P<0.05)$.

3.5. Principal Component Analysis. The PCA was carried out with 18 quality indexes of 21 sorghum varieties, including moisture, protein, starch, fat, tannin, ash, iodine blue value, expansion volume, water absorption rate, $\mathrm{PT}, \mathrm{PV}, \mathrm{BD}, \mathrm{SB}$, hardness, stickiness, adhesiveness, chewiness, and responsiveness which were expressed by $X_{1}-X_{18}$, respectively.

A scree plot that identifies the major groups of variables was done. The scree plot is shown in Figure 2. The first five principal components $F_{1}-F_{5}$ had a high total variability equal to $86.19 \%$ and were considered representative of the data and further investigated. The component $F_{1}$ is clearly the most significant principal component.

The loadings of the individual variables in each PC were done (Table 3), in order to investigate the correlations among the five main variables $F_{1}-F_{5}$ and their components. The contribution rate of each index variable $X_{\mathrm{i}}$ to $F_{\mathrm{j}}$ was calculated and sorted. The first $n$ index variables with a cumulative contribution rate of more than $85 \%$ to $F_{j}$ were selected for the interpretation and analysis of $F_{\mathrm{j}}$ [46]. The results are shown in Table 4. Combining Tables 3 and 4 , it could be seen that $X_{16}$, $X_{17}, X_{10}, X_{3}, X_{2}, X_{8}, X_{14}, X_{18}, X_{15}, X_{12}$, and $X_{13}$ were grouped within $F_{1}$ and can be treated as one variable. And so on, the relationship between other variables and principal components could be obtained. Among them, $F_{1}$ mainly synthesized the variation information of protein content $X_{2}$, starch content $X_{3}$, PT $X_{10}$, adhesiveness $X_{16}$, and chewiness $X_{17}$ with the variance of $0.54,0.63,0.81,0.86$, and 0.83 , respectively, which were more than $50 \%$ and related to the texture of sorghum rice. $F_{2}$ was mainly characterized in PV $X_{11}, \mathrm{SD} X_{12}, \mathrm{SB} X_{13}$, hardness $X_{14}$, and stickiness $X_{15}$, which were related to the change of the gelatinization property in the sorghum cooking process. The tannin content $X_{5}$ and ash content $X_{6}$ have the largest contribution rate to $F_{3}$, while the high tannin content will produce bitter taste, mainly affecting the flavor of sorghum. Volume expansion ratio $X_{8}$ and water absorption ratio $X_{9}$ are the main contribution variables to $F_{4}$, which were related to cooking characteristics. The moisture $X_{1}$ and iodine blue value $X_{7}$ have the largest contribution rate to $F_{5}$, and these two indexes were related to the waxy and nonwaxy varieties of sorghum. Therefore, $F_{5}$ mainly reflected the quality of sorghum varieties.

According to the results of PCA, the eigenvectors of the five PC were further calculated, as shown in Table 5. Then, the linear relationship was obtained as follows:

$$
Z=0.45 F_{1}+0.25 F_{2}+0.12 F_{3}+0.10 F_{4}+0.08 F_{5} .
$$

21 kinds of sorghum were evaluated by the equation, and the two varieties with the highest score were No. 14 and No. 15 cultivated in Heilongjiang.

Finally, in order to verify the accuracy and practicability of the equation, the sensory evaluation was taken as the ordinate and the comprehensive evaluation equation as the horizontal coordinate, and the linear regression analysis was used to verify the edible quality of sorghum rice. The formula was obtained, as follows:

$$
y=3.42 x+70.24\left(r^{2}=0.81\right)
$$


TABLE 4: Contribution rate (CR) and cumulative contribution rate (CCR) of individual variables (IV) to PC.

\begin{tabular}{|c|c|c|c|c|c|c|c|c|c|c|c|c|c|c|}
\hline \multirow{2}{*}{ IV } & \multicolumn{2}{|c|}{$F_{1}$} & \multirow{2}{*}{ IV } & \multicolumn{2}{|c|}{$F_{2}$} & \multirow{2}{*}{ IV } & \multicolumn{2}{|c|}{$F_{3}$} & \multirow{2}{*}{ IV } & \multicolumn{2}{|c|}{$F_{4}$} & \multirow{2}{*}{ IV } & \multicolumn{2}{|c|}{$F_{5}$} \\
\hline & CR (\%) & CCR (\%) & & CR (\%) & CCR (\%) & & CR (\%) & CCR (\%) & & CR (\%) & CCR (\%) & & CR (\%) & CCR (\%) \\
\hline$X_{16}$ & 12.30 & 12.30 & $X_{11}$ & 18.35 & 18.35 & $X_{5}$ & 43.89 & 43.89 & $X_{9}$ & 34.53 & 34.53 & 1 & 32.38 & 32.38 \\
\hline$X_{17}$ & 11.94 & 24.24 & $X_{13}$ & 11.72 & 30.07 & $X_{6}$ & 9.92 & 53.81 & $X_{8}$ & 23.74 & 58.27 & 7 & 22.41 & 54.79 \\
\hline$X_{10}$ & 11.62 & 35.86 & $X_{15}$ & 9.44 & 39.50 & $X_{11}$ & 9.12 & 62.93 & $X_{6}$ & 13.14 & 71.41 & 4 & 19.51 & 74.30 \\
\hline$X_{3}$ & 9.08 & 44.94 & $X_{12}$ & 9.01 & 48.51 & $X_{7}$ & 8.14 & 71.07 & $X_{18}$ & 7.61 & 79.02 & 5 & 6.20 & 80.50 \\
\hline$X_{2}$ & 7.71 & 52.65 & $X_{14}$ & 8.63 & 57.15 & $X_{12}$ & 6.65 & 77.72 & $X_{15}$ & 6.73 & 85.74 & 14 & 4.54 & 85.04 \\
\hline$X_{8}$ & 6.54 & 59.18 & $X_{1}$ & 8.20 & 65.34 & $X_{4}$ & 5.62 & 83.33 & & & & & & \\
\hline$X_{14}$ & 6.35 & 65.53 & $X_{2}$ & 6.54 & 71.89 & $X_{17}$ & 4.37 & 87.70 & & & & & & \\
\hline$X_{18}$ & 6.02 & 71.56 & $X_{18}$ & 6.37 & 78.26 & & & & & & & & & \\
\hline$X_{15}$ & 5.90 & 77.45 & $X_{4}$ & 5.96 & 84.22 & & & & & & & & & \\
\hline$X_{12}$ & 5.59 & 83.05 & $X_{7}$ & 5.24 & 89.46 & & & & & & & & & \\
\hline$X_{13}$ & 4.66 & 87.71 & & & & & & & & & & & & \\
\hline
\end{tabular}

TABLE 5: Eigenvector of primary components.

\begin{tabular}{|c|c|c|c|c|c|}
\hline \multirow{2}{*}{ Individual variable } & \multicolumn{5}{|c|}{ Principal component function } \\
\hline & $F_{1}$ & $F_{2}$ & $F_{3}$ & $F_{4}$ & $F_{5}$ \\
\hline$\overline{X_{1}}$ & -0.095 & 0.286 & -0.129 & 0.229 & 0.569 \\
\hline$X_{2}$ & 0.278 & -0.256 & 0.055 & 0.074 & -0.116 \\
\hline$X_{3}$ & 0.301 & 0.134 & 0.031 & 0.090 & 0.121 \\
\hline$X_{4}$ & -0.139 & -0.244 & 0.237 & 0.109 & 0.442 \\
\hline$X_{5}$ & 0.022 & 0.025 & -0.663 & 0.021 & -0.249 \\
\hline$X_{6}$ & 0.163 & -0.071 & -0.315 & -0.362 & 0.197 \\
\hline$X_{7}$ & 0.185 & 0.229 & -0.285 & -0.036 & 0.473 \\
\hline$X_{8}$ & 0.256 & 0.129 & -0.095 & 0.487 & -0.072 \\
\hline$X_{9}$ & 0.152 & 0.201 & -0.098 & 0.588 & -0.188 \\
\hline$X_{10}$ & 0.341 & -0.061 & 0.077 & -0.049 & -0.036 \\
\hline$X_{11}$ & -0.102 & 0.428 & 0.302 & -0.020 & -0.011 \\
\hline$X_{12}$ & -0.237 & 0.300 & 0.258 & 0.096 & -0.124 \\
\hline$X_{13}$ & 0.216 & 0.342 & 0.150 & -0.181 & -0.009 \\
\hline$X_{14}$ & 0.252 & -0.294 & 0.129 & 0.130 & 0.213 \\
\hline$X_{15}$ & 0.243 & 0.307 & -0.002 & -0.259 & 0.015 \\
\hline$X_{16}$ & 0.351 & -0.109 & 0.177 & 0.016 & 0.036 \\
\hline$X_{17}$ & 0.346 & -0.097 & 0.209 & 0.028 & -0.014 \\
\hline$X_{18}$ & 0.245 & 0.252 & 0.084 & -0.276 & -0.154 \\
\hline
\end{tabular}

and the fitting coefficient was greater than 0.80 , which indicated that the equation can accurately evaluate the edible quality of sorghum rice.

\section{Conclusions}

One-way ANOVA analysis of 18 indicators of 21 kinds of sorghum from the Northeast China revealed that there were significant differences among the quality characteristics of different varieties. Meanwhile, it could be seen that there were regional differences of the starch content, protein content, and PT. And the above indicators of sorghum varieties from Heilongjiang are generally lower than those from Jilin. Then, five principal components with a cumulative contribution rate of $86.19 \%$ could be picked out by PCA to describe the taste, pasting, flavor, cooking, and variety of sorghum, respectively. According to the results of PCA, a comprehensive equation was constructed, which is $Z=0.45 F_{1}+0.25 F_{2}+0.12 F_{3}+0.10 F_{4}+0.08 F_{5}$, and two sorghum varieties with the highest score were obtained: No. 14 and No. 15. Meanwhile, the sensory quality analysis was used to verify the equation with the fitting coefficient of 0.81
$(>0.80)$, which indicated that the five principal components $\left(F_{1}-F_{5}\right)$ could be more accurate to evaluate the edible quality of sorghum.

\section{Data Availability}

The data used to support the findings of this study are included within the article.

\section{Ethical Approval}

All procedures performed in studies involving human participants were in accordance with the ethical standards of the institutional and national research committee and with the 1964 Helsinki declaration and its later amendments or comparable ethical standards.

\section{Consent}

Informed consent was obtained from all individual participants included in the study. 


\section{Conflicts of Interest}

The authors declare that there are no conflicts of interest.

\section{Acknowledgments}

The authors are thankful to Jilin Academy of Agricultural Sciences (Jilin Province, China) and Heilongjiang Academy of Agricultural Sciences (Heilongjiang Province, China) for providing sorghum varieties. This study was funded by the Project of National Key Technology Research and Development Program from the 13th Five-Year Plan (grant no. 2017YFD0401204).

\section{References}

[1] Food and Agricultural Organization, Food and Agriculture Organization Corporate Statistical Database (Faostat), Food and Agricultural Organization, Rome, Italy, 2010.

[2] L. D. Moraiscardoso, S. S. Pinheiro, H. S. D. Martino, and H. M. A. Pinheiro-Sant, "Sorghum (Sorghum bicolor L.): nutrients, bioactive compounds, and potential impact on human health," Critical Reviews in Food Science and Nutrition, vol. 57, no. 2, pp. 372-390, 2015.

[3] J. Taylor and P. Shewry, "Preface to sorghum and millets reviews," Journal of Cereal Science, vol. 44, no. 3, p. 223, 2006.

[4] J. W. Vargas-Solórzano, C. W. P. Carvalho, C. Y. Takeiti, J. L. R. Ascheri, and V. A. V. Queiroz, "Physicochemical properties of expanded extrudates from colored sorghum genotypes," Food Research International, vol. 55, pp. 37-44, 2014.

[5] A. E.-M. M. R. Afify, H. S. El-Beltagi, S. M. A. El-Salam, and A. A. Omran, "Bioavailability of iron, zinc, phytate and phytase activity during soaking and germination of white sorghum varieties," PLoS One, vol. 6, no. 10, Article ID e25512, 2011.

[6] A. Akinfemi, O. A. Adu, and F. Doherty, "Conversion of sorghum stover into animal feed with white-rot fungi: Pleurotus ostreatus and Pleurotus pulmonarius," African Journal of Biotechnology, vol. 9, no. 11, pp. 1706-1712, 2010.

[7] V. Taleon, L. Dykes, W. L. Rooney, and L. W. Rooney, "Effect of genotype and environment on flavonoid concentration and profile of black sorghum grains," Journal of Cereal Science, vol. 56, no. 2, pp. 470-475, 2012.

[8] Q. Peng, R. Tian, F. Chen, B. Li, and H. Gao, "Discrimination of producing area of Chinese Tongshan kaoliang spirit using electronic nose sensing characteristics combined with the chemometrics methods," Food Chemistry, vol. 178, pp. 301305, 2015.

[9] K. Wilkie, M. Wootton, and J. E. Paton, "Sensory testing of Australian fragrant, imported fragrant, and non-fragrant rice aroma," International Journal of Food Properties, vol. 7, no. 1, pp. 27-36, 2004.

[10] A. M. Odenigbo, M. Ngadi, C. Ejebe, N. Woin, and S. A. Ndindeng, "Physicochemical, cooking characteristics and textural properties of TOX 3145 milled rice," Journal of Food Research, vol. 3, no. 2, p. 82, 2014.

[11] M. Okabe, "Texture measurement of cooked rice and its relationship to the eating quality," Journal of Texture Studies, vol. 10, no. 2, pp. 131-152, 2010.

[12] E. T. Champagne, K. L. Bett, B. T. Vinyard et al., "Correlation between cooked rice texture and rapid visco analyser measurements," Cereal Chemistry Journal, vol. 76, no. 5, pp. 764-771, 1999.

[13] Y. Guo, F. LI, Y. Hong, and Y. Liu, "Study on the correlation between properties of rice and the quality of cooked rice," Journal of Wuhan Polytechnic University, vol. 34, no. 3, pp. 1-6, 2015.

[14] X.-Z. Han and B. R. Hamaker, "Amylopectin fine structure and rice starch paste breakdown," Journal of Cereal Science, vol. 34, no. 3, pp. 279-284, 2001.

[15] D. Mohapatra and S. Bal, "Cooking quality and instrumental textural attributes of cooked rice for different milling fractions," Journal of Food Engineering, vol. 73, no. 3, pp. 253-259, 2006.

[16] S. J. Bhonsle and K. Sellappan, "Grain quality evaluation of traditionally cultivated rice varieties of Goa, India," Recent Research in Science and Technology, vol. 2, no. 3, pp. 88-97, 2010.

[17] S. K. Jain and P. R. Patel, "Principal component and cluster analysis in sorghum (Sorghum bicolor (L.) Moench)," Forage Research, vol. 42, pp. 90-95, 2016.

[18] C. Mestres, F. Ribeyre, B. Pons, V. Fallet, and F. Matencio, "Sensory texture of cooked rice is rather linked to chemical than to physical characteristics of raw grain," Journal of Cereal Science, vol. 53, no. 1, pp. 81-89, 2011.

[19] M. Osawa and N. Inoue, "Principal component analysis of starch digestibility and physicochemical properties related to texture of rice (quality and processing)," Japanese Journal of Crop Science, vol. 77, no. 1, pp. 61-68, 2008.

[20] H. Li, X. Li, Z. Ma, J. Li, X. Hu, and C. Ren, "Relationships between oat kernel,physicochemical and processing parameters," Journal of Triticeae Crops, vol. 35, pp. 499-507, 2015.

[21] Y. Liu, J. Song, D. LI, C. Liu, and B. Jin, "Principal component analysis during variety screening for instant corn," Food Science, vol. 31, pp. 71-73, 2010.

[22] L. Lu and Z. Zhu, "Prediction model for eating property of Indica rice," Journal of Food Quality, vol. 37, no. 4, pp. 274-280, 2014.

[23] L. Wang, Y. Liu, and S. Zhao, "Quality improvement and evaluation model of rice cake," Journal of the Chinese Cereals and Oils Association, vol. 31, no. 5, pp. 122-127, 2016.

[24] M. Zhu, N. Xiong, H. Liu et al., "Establishment of models to evaluate the eating quality and comprehensive quality of Indica rice," Food Science, vol. 37, pp. 97-103, 2016.

[25] E. D. Maxson and L. W. Rooney, "Evaluation of methods for tannin analysis in sorghum grain," Cereal Chemistry, vol. 49, no. 6, pp. 719-729, 1972.

[26] J. Bao, "Accurate measurement of pasting temperature by the rapid visco-analyser: a case study using rice flour," Rice Science, vol. 15, no. 1, pp. 69-72, 2018.

[27] Z. Wang, Quality Analysis of Grain, Oil and Food, China Light Industry Press, Beijing China, 2000.

[28] C. Liu, Y. Sun, D. Wang et al., "Performance and mechanism of low-frequency ultrasound to regenerate the biological activated carbon," Ultrasonics Sonochemistry, vol. 34, pp. 142-153, 2017.

[29] S. Yu, Y. Ma, and D.-W. Sun, "Impact of amylose content on starch retrogradation and texture of cooked milled rice during storage," Journal of Cereal Science, vol. 50, no. 2, pp. 139-144, 2009.

[30] M. Góral, K. Kozłowicz, U. Pankiewicz, D. Góral, F. Kluza, and A. Wójtowicz, "Impact of stabilizers on the freezing process, and physicochemical and organoleptic properties of coconut milk-based ice cream," LWT, vol. 92, pp. 516-522, 2018. 
[31] A. Kurt and I. Atalar, "Effects of quince seed on the rheological, structural and sensory characteristics of ice cream," Food Hydrocolloids, vol. 82, pp. 186-195, 2018.

[32] F. Artoni, A. Delorme, and S. Makeig, "Applying dimension reduction to EEG data by principal component analysis reduces the quality of its subsequent independent component decomposition," NeuroImage, vol. 175, pp. 176-187, 2018.

[33] M. Zhang and H. Liu, "Assessment model of taste quality of millet based on principal component analysis method," Journal of Northeast Agricultural University, vol. 42, pp. 7-12, 2011.

[34] H. Wang, Research on Cooking Characteristics Andimproved Technology of Coix Seed, Southwest University, Chongqing, China, 2014.

[35] W. Srisawas and V. K. Jindal, "Sensory evaluation of cooked rice in relation to water-to-rice ratio and physicochemical properties," Journal of Texture Studies, vol. 38, no. 1, pp. 21-41, 2010.

[36] K. Larsson, "Inhibition of starch gelatinization by amylose-lipid complex formation. Behinderung der Stärkeverkleisterung durch Bildung eines Amylose-Lipidkomplexes," Starch-Stärke, vol. 32 , no. 4 , pp. $125-126,1980$.

[37] A. Chandashekar and A. W. Kirleis, "Influence of protein on starch gelatinization in sorghum," Cereal Chemistry, vol. 65, pp. 457-462, 1988.

[38] X. Mo, D. Qu, and J. Han, "Study on japonica rice starch and its gelatinization properties and edible quality of cooked rice," Science \& Technology of Food Industry, 2014.

[39] X. Zhou, J. Sun, Y. Zhang, Y. Liu, and J. Gao, "Relationships between three-point bending mechanical properties with cooking and edible quality of rice," Modern Food Science \& Technology, vol. 32, pp. 35-41, 2016.

[40] P. Leelayuthsoontorn and A. Thipayarat, "Textural and morphological changes of Jasmine rice under various elevated cooking conditions," Food Chemistry, vol. 96, no. 4, pp. 606-613, 2006.

[41] K. Cheng, Physicochemical Characteristics and Molecular Structure and Their Correlation in Rice Starch, Huazhong Agricultural University, Wuhan, China, 2006.

[42] X. Tian, B. Tan, H. Tian, and M. Liu, "Properties of sorghum starches from twenty varieties in China," Food Science, vol. 31, pp. 13-20, 2010.

[43] C. E. Chávez-Murillo, Y.-J. Wang, A. G. Quintero-Gutierrez, and L. A. Bello-Pérez, "Physicochemical, textural, and nutritional characterization of Mexican rice cultivars," Cereal Chemistry Journal, vol. 88, no. 3, pp. 245-252, 2011.

[44] X. Zhou, Study on Eating Qualities Analysis and Comprehensive Evaluation of Rice with Different Milling Degree, College of Life Sciences and Food Engineering, Nanchang University Nanchang, Nanchang, China, 2013.

[45] T. Huang, W. Wu, G. LI, and X. Feng, "Research on relativity between rice's physical-chemical properties and mouth-feel quality," Food and Nutrition in China, vol. 18, pp. 24-28, 2012.

[46] F. Zhao, Quality Analyses of Oat Varieties and Processing Suitability for Oats Fermented Milk Graduate School of Agricultural Products Processing Institute, Chinese Academy of Agricultural Sciences Dissertation, Beijing, China, 2016. 

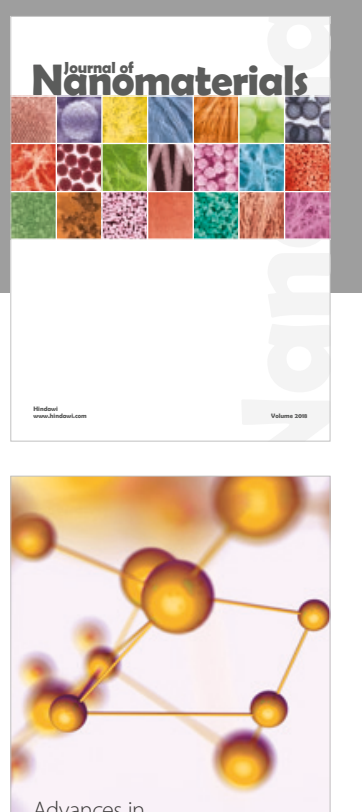

Physical Chemistry
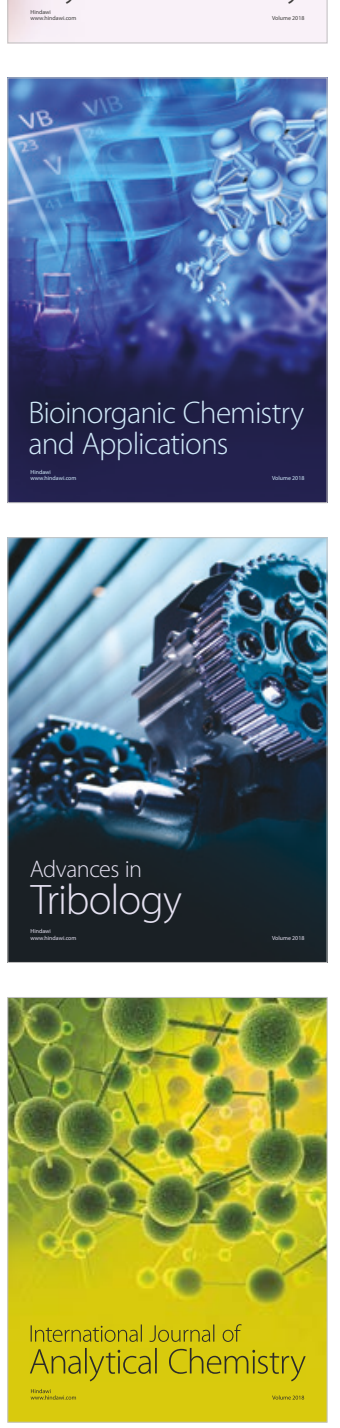

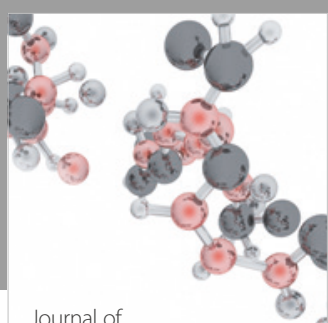

Analytical Methods

in Chemistry

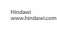

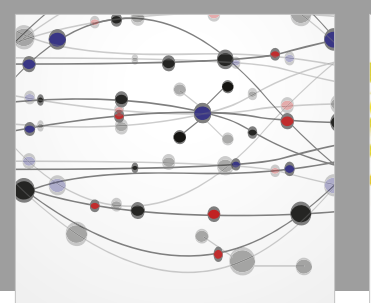

The Scientific World Journal

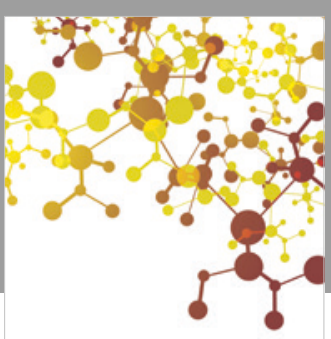

Journal of

Applied Chemistry
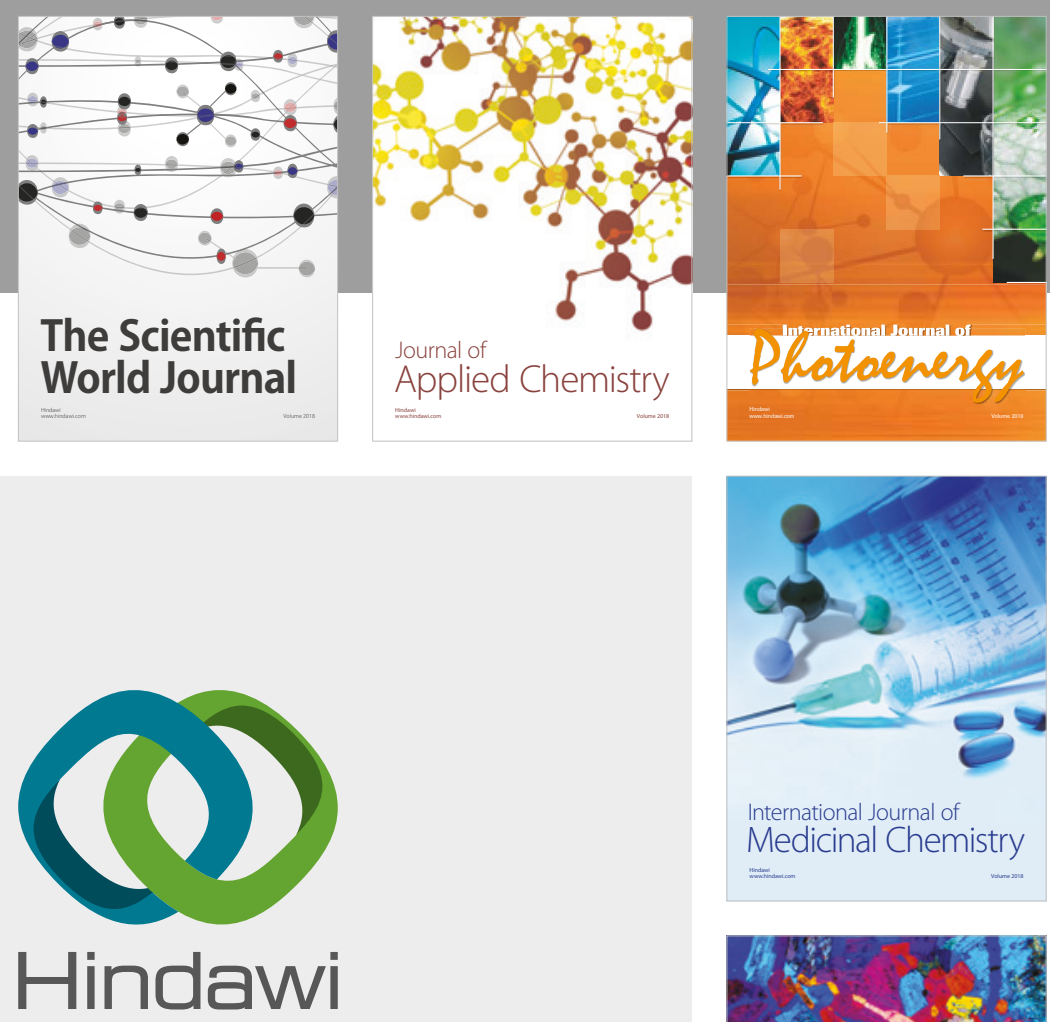

Submit your manuscripts at

www.hindawi.com
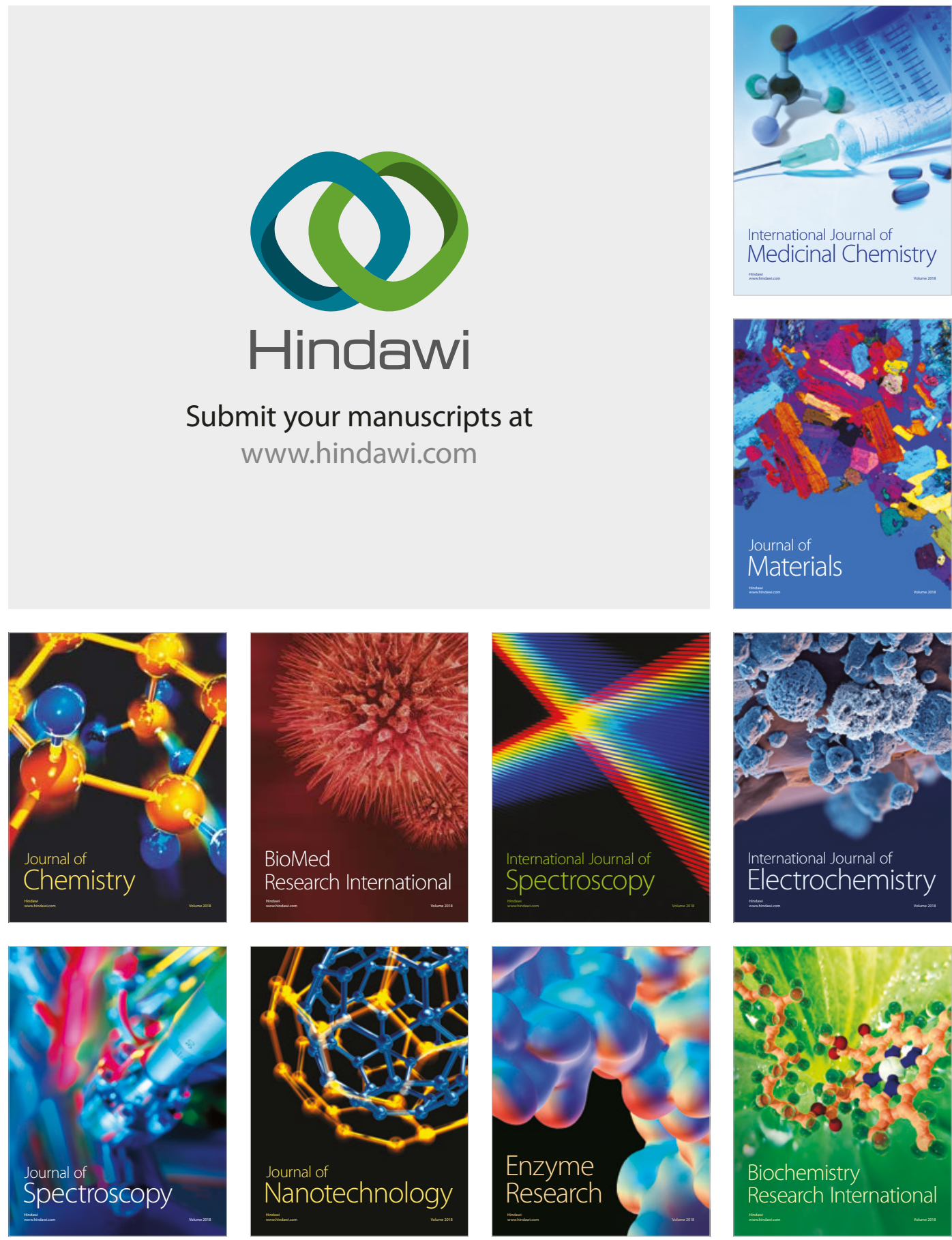
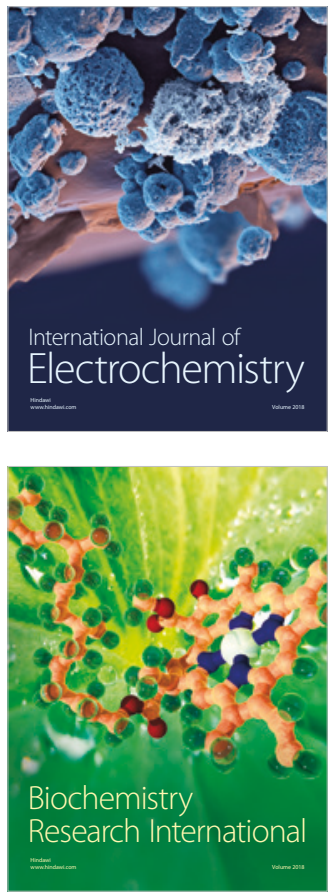